\title{
THE RECORDING OF HIGH SPEED SIGNALS IN RADIO TELEGRAPHY*
}

\author{
$\mathrm{BY}$ \\ JULIUS WEINBERGER \\ (Research Engineer, Research Department, Radio Corporation of \\ AMERICA)
}

\section{INFRODUCTION}

In this paper it is proposed to deal with the development and operation of a practical system for the handling of radio telegraphic traffic at high speed, particularly in trans-oceanic communication. By high speed working we refer to operation at speeds greater than those customarily employed for telephonic reception, that is 20 to 25 words per minute by average good operators.

With the continually increasing expensiveness of equipment, and the tendency towards increase of transmitting power (so as to insure reliable communication at all times), it has become apparent that the profitable operation of a long distance radio system depends greatly upon working at a rate of speed in excess of that obtainable by hand. Most of the high power radio transmitters of today are equipped with relay systems capable of sending as high as 100 words per minute, and there is no particular reason why, if necessary, powerful vacuum tube amplifiers could not be built to take the place of relays and be worked at considerably greater speed. The limitation of working speed is practically confined to the receiving side of the radio system, so that it is obvious that increased speed possibilities must be obtained entirely by the development of receiving apparatus.

In order to understand the conditions under which high speed recording apparatus must work, it will be well to describe briefly the manner in which communication is carried on over the transAtlantic circuits of the Radio Corporation. Figure 1 illustrates the method of duplex working. It will be noted that the operation is from New York City, while the transmitting and receiv-

${ }^{*}$ Received by the Editor, November 12, 1921. Presented before THE Institute of Radio EnaineERs, New York, December 7, 1921. 
ing stations are placed at some suitable distant point; and it is intended to concentrate most of the Atlantic Coast transmitters in a central plant at Port Jefferson, Long Island, while most of the receivers are concentrated at Riverhead (about 18 miles $(29 \mathrm{~km}$.) from Port Jefferson). All control of the various trans-

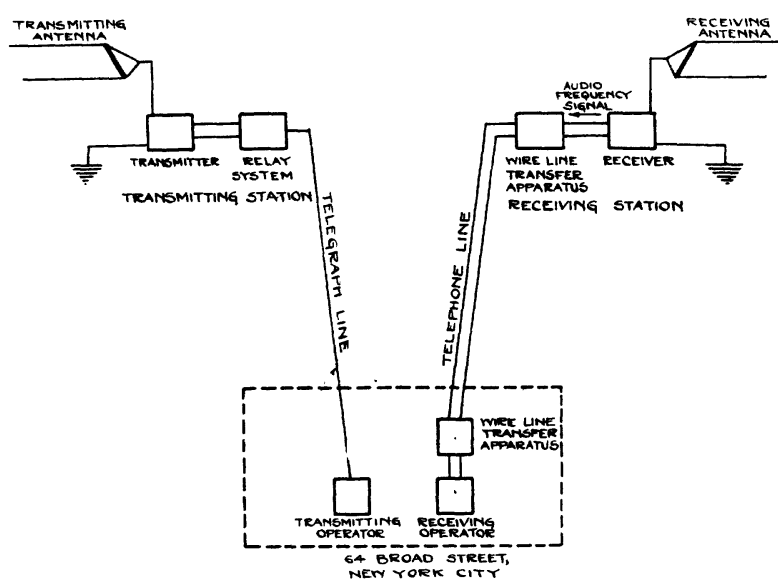

Figure 1-Radio Corporation of America: Method of Centralized Operation

mitters and receivers is from New York City, the sending operator controlling a transmitter via telegraph line and the receiving operator having the received audio frequency signal brought to him via telephone line. The transmitting and receiving operators are located close to one another (at a common table), so as to facilitate duplex operation. The receiving operator can thus instantly communicate with the distant transmitter, if desired, in order to control the speed of transmission, or stop the transmission in case of trouble. The operators themselves handle no apparatus whatsoever; the receiving and transmitting apparatus is handled by engineers at the respective stations, and such apparatus as is necessary for wire line transfer at Broad Street is placed in a room separate from the operating room and maintained by men of suitable qualifications.

\section{Requirements of High Speed Recording Apparatus}

The foregoing operating arrangement, as well as certain service standards, imposes a series of requirements upon high speed recording apparatus which are given below: 
1. Minimum delay between the time of recording and the time of transcribing the signals. This is of importance in

(a) Successful duplex operation: In case of trouble (for example, bad relay adjustment in the transmitting station) or for other reasons, it may become necessary to stop the distant transmitter. If the record is not immediately perceptible, a considerable quantity of traffic might be sent which was not properly recorded, and which would then have to be repeated, with consequent loss of circuit time and delay in delivery.

(b) Prompt delivery of messages to the customer

(c) Observation of the effect of adjustment of the receiving or transmitting apparatus. It is essential that a minimum delay shall occur between the time a change of adjustment is made and the time the effect of the change is perceived.

2. The cost of recording must be as low as possible-not over a few hundredths of a cent per word. This is important since a large class of reduced rate traffic, such as press matter, deferred delivery messages, and the like, is handled at high speed. Furthermore, the future operating of short distance radio circuits with low rates must be taken into consideration, since the equipment designed for long distance working should be standardized for all classes of service if possible. Therefore the initial cost of the equipment must be low, as well as the operating and maintenance charges.

3. The recording equipment must be as simple and rugged as possible, and require no continuous attention; since it must be located near the receiving operators and handled by the telegraph supervisors, who generally do not have extensive technical or engineering qualifications. The parts of which the equipment is constructed should be capable of easy repair in case of breakage, as far as possible, by the men and facilities available in the operating rooms, and spare parts should be capable of easy installation by such men. This is more important when recording equipment is furnished to stations other than those located in New York City (such as those in Hawaii or on the Pacific Coast), to which it would be manifestly very expensive to send expert repair men.

4. A record capable of preservation is highly desirable, so as to check up errors, and for use as a means of traffic study and general service improvement.

5. The tone signal which is sent over the telephone line from the receiving set may be anywhere between 500 and 1,500 cycles. (Altho the lines will transmit, theoretically. frequencies up to 
2,200 cycles, it has been found in practice that better transmission is secured by keeping signals below about 1,500 cycles). The recording equipment must be capable of accepting any given frequency in this range, and allow for a considerable fluctuation above or below this frequency. It has been found in practice that at present frequency fluctuations of several hundred cycles must be taken into account with some European transmitters; tho improvements in this respect no doubt will be made. A fluctuation of signal intensity of the order of perhaps 2 to 1 must be taken into account, due to accidental changes in line conditions, amplifier adjustments, or during tuning of the receiving equipment at the distant station.

6. Speed Limitations: Present practice in long distance high speed working is on the basis of from 40 to 50 words (200 to 250 letters) per minute, and at times higher speeds, up to 80 words per minute, have been commercially handled. The limitation lies in relay trouble at the transmitting end and strays at the receiving end of the circuit. It is probable that working at 100 words per minute will eventually become the rule tho not for a number of years. Hence, a recording system should be able to handle easily speeds up to 80 words per minute, and be so designed that extension to higher speeds (say, up to 200 words per minute) can be accomplished by simple modifications, for use on short-distance circuits. It is interesting to note, in this connection, that European short-distance radio circuits (for example, London-Paris, and London-Berlin), are understood to be operating regularly at 60 words per minute, and operation up to 100 words per minute has been carried on at times.

7. The perception of the recorded signal by the operator should be made as easy as possible. The operator has not the time to study the record, and an easily perceived record at lower speeds is preferable to one at a higher speed which requires study on his part. For example, in graphic recorders the contrast between recorded signal and background should be great, the letters clean-cut, so that the operator perceives them instantly, and static eliminated from the record to the maximum extent consistent with accuracy. In acoustic recorders (such as the phonograph or the telegraphone) the signal heard by the transcribing operator must be clear and loud, free from musical static and with firmly-formed dots and dashes. It is difficult to overestimate the importance of this requirement; it has a great influence on commercially successful operation, for the speed at 
which operators will handle traffic depends considerably on the clearness of the signals with which they deal.

8. The effort necessary, on the part of the operator, to distinguish the signal from such record as may be produced by static, in the ideal case, should be equal to or less than that necessary for aural reception with head telephones.

9. Continuous operation of the recording equipment is essential. In the case of acoustic recorders, where it takes some time to place a new record on the machine, two overlapping recorders must be used, one being started just before the record is removed from the other. But the installation of two machines is uneconomical and continuous operation should be provided for, in the ideal recorder, in a single machine.

\section{Available Types of Recording Equipment}

When the Research Department started on the developmen of a commercially practical and modern high speed reception system there were available a number of different types of recording apparatus, which were taken under consideration. These may be divided into two general classes, namely acoustic and graphic recorders. We will consider these below:

\section{(A) Acoustic Recorders}

This type of recorder is connected to the radio receiving set in place of the operator's telephones; and generally some audio frequency amplification ahead of the recorder is required so as to overcome the losses occurring in the recording and reproducing process. The particular advantage in acoustic recording methods is that the experience of the operators in reading signals thru strays by ear is utilized. When recording high speed signals, the tone of the received signal is raised to a high pitch at the receiving set by appropriate adjustment, and the machine run at its maximum speed; for reproducing, the speed of the machine is lowered and the tone of the reproduced signal is, of course, lower in proportion. For example, in phonographic recorders it is customary to reproduce with the record rotating at about 100 revolutions per minute at a note of, say 800 cycles, and a speed of about 15 words per minute. Then when recording 80 words per minute, the record as rotated at 400 revolutions per minute, and a recording tone of 3,200 cycles must be used.

A typical acoustic recording and transcribing installation comprises two recording machines (so as to afford continuous operation and numerous reproducing machines. The records 
are distributed from the recorders to operators at the various reproducers for transcription.

Two types of acoustic recorders have been used to some extent in radio practice. The first of these is the well-known Poulsen telegraphone, in which a steel wire runs at high speed past a pair of electromagnets thru which the audio frequency current to be recorded flows: The record is in the form of magnetic charges which remain fixed on the wire. In other types, which were not available in this country, the record is made on a disk, or on a cylinder, similar in nature to the records used in disk or cylinder phonographs. It is possible to erase the record by a suitable uniform magnetisation of the steel. Figure 2 shows the type of wire telegraphone which has been used ra dio reception.

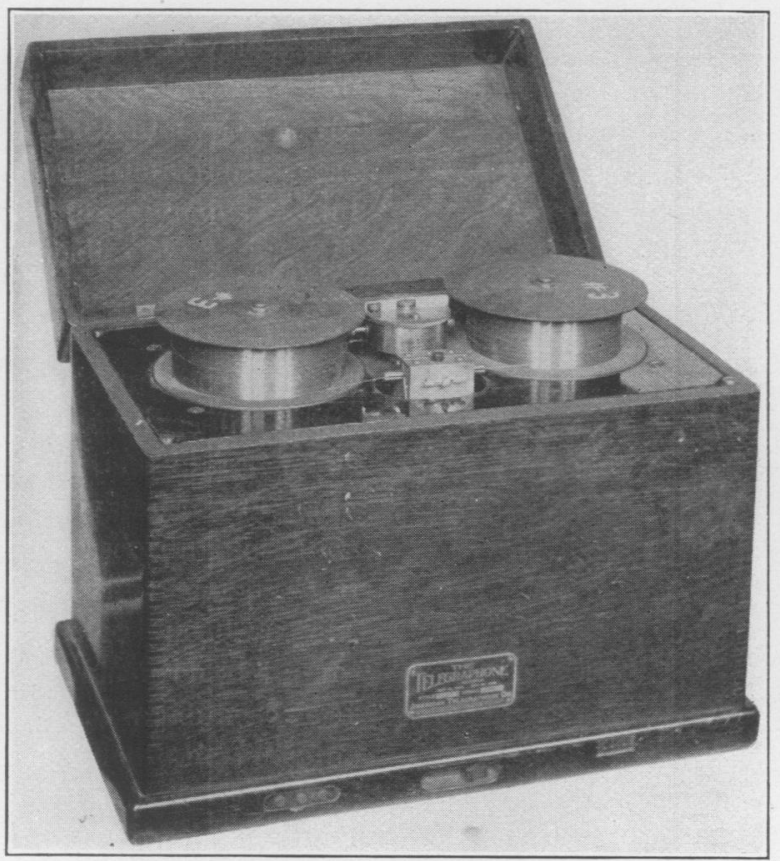

Figure 2-Steel Wire Telegraphone

The second type of recorder is the phonograph; this has been employed in the form of an ordinary office dictating machine (in this country the "Dictaphone" and the "Ediphone" have both given good service) with cylindrical wax records. The signal from the receiving set is brought to a special telephone receiver (hav- 
ing a highly damped diafram so as to reduce the musicality of the record due to strays) after passing thru an amplifier giving several hundred times voltage amplification. This receiver is mounted directly on the intake of the recording head. In Figure 3 , the method of recording and, in Figure 4, the method of transcribing are shown.

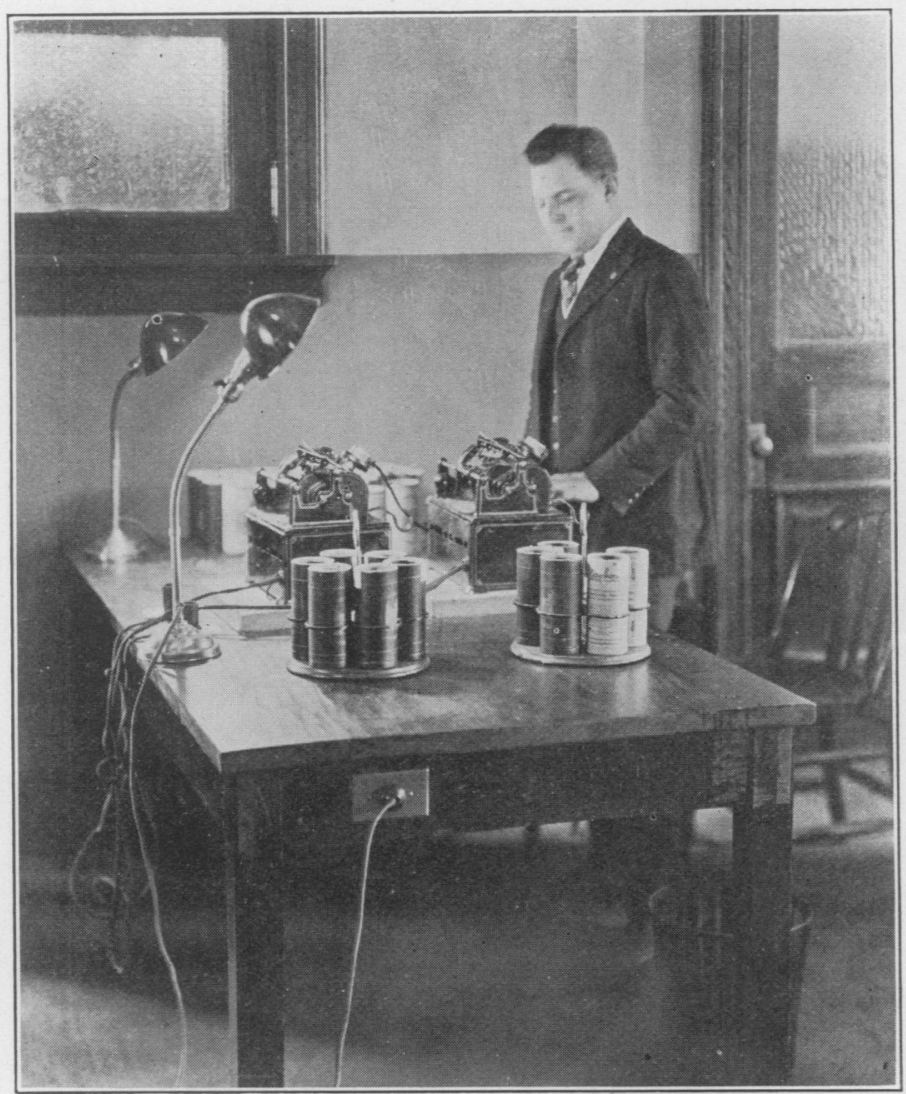

Figure 3-Phonographic High Speed Recording

Both varieties of acoustic recorders have a number of inherent defects and disadvantages. These are considered under the following headings:

\section{(1) Delay in Obtaining Transcribed Messages}

In the steel wire telegraphone, as ordinarily constructed for office work, a very large amount of wire is supplied; so that a period of approximately half an hour elapses before the recorded 
signals are available for transcription. This length of time is quite prohibitive from an operating standpoint.

In the phonograph, from four to six minutes elapse between the time of recording and transcription, which is still considered as unsatisfactory. In both these cases the time is objectionable because of the delay in the delivery of messages and the difficulty of adequate supervision of the quality of the recorded signal.

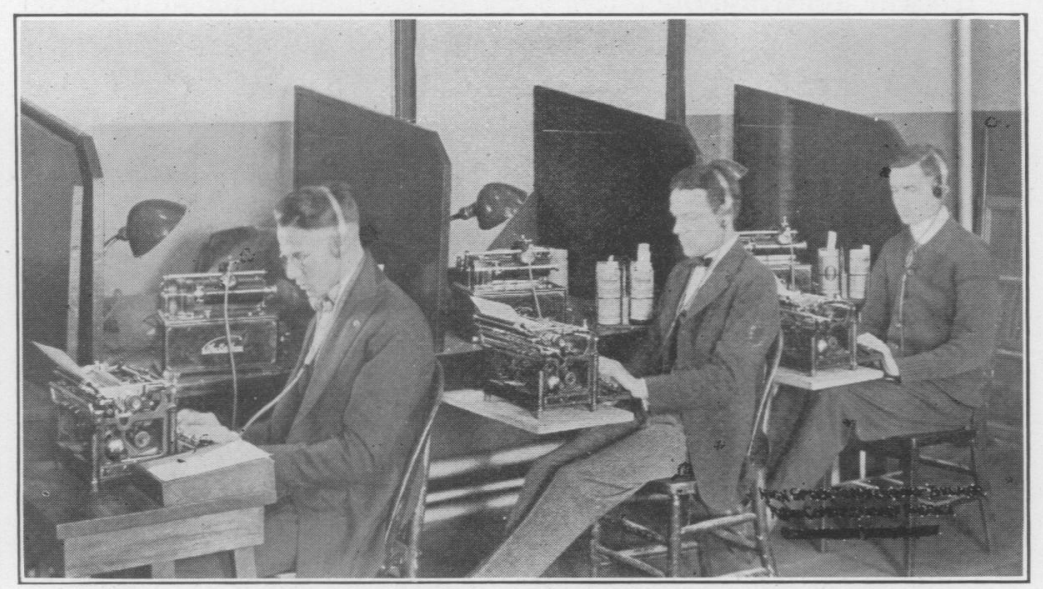

Figure 4-Transcribing Phonographic High Speed Records

\section{(2) Cost}

An acoustic recording installation requires two recording machines and from four to six transcribing machines; in operation, one man is required to attend the recorders (put on and take off records), one man to erase previous records (operating shaving machine in the case of phonographs or erasing machine with telegraphones) and distribute records to the transcribing operators, and four or six transcribers. Thus the installation and operating cost of this type of system is extremely high. As will be shown later, cost is reduced to a minimum in the present type of recording system developed by the Research Department.

\section{(3) Lack of Permanent Record}

This is an important disadvantage in acoustic recording systems. It is highly desirable to preserve a record of the received messages, so as to place responsibility for errors, and as a means of studying the quality of received signals. If this were done with acoustic recording systems, the operating cost would be prohibitive, because of the expense of the record blanks. 
Thus, it is necessary to erase the recorded messages (by shaving in the case of the wax phonograph cylinder, or magnetic erasure on the telegraphone wire); and this is generally done immediately after transcribing, so that operation may be carried on with a minimum quantity of blanks.

\section{(4) Mechanical Disadvantages:}

In the telegraphone, the steel wire running at high speed sometimes breaks. When this happens it is possible that it may become rather badly snarled and it may be impossible to recover a considerable quantity of the tangled wire in order to transcribe it, while the repairing of the broken wire necessitates rather expert attention.

In the phonographic office dictating machines considerable ingenuity has been expended to make them "fool-proof;" but they still require careful and continuous attention in order to make them give the best records.

Both the telegraphone and phonographs require an expert repair man in case of trouble, contain a multitude of parts, and should have a periodic overhauling. In the case of controlstation operation in New York City this is not so serious, but it is undesirable for more isolated stations.

\section{(5) Limitations of Usefulness in Central Station Oper- ation with Wire Line Transfer}

In the method of operation shown in Figure 1, it has been mentioned that it is advisable to remain below 1,500 cycles for the pitch of the audio frequency signal transmitted over the telephone line. This imposes a serious speed limitation on acoustic recording systems because of the necessity of lowering the pitch for transcribing. Assuming transcription to occur at 800 cycles and 20 words per minute, this system would be limited at best to a speed of about 40 words per minute.

\section{(B) Graphic RECORDERS}

Two main classes of graphic recorders may be taken under consideration:

(1) The photographic type, in which the signals are recorded on photographic paper.

(2) The stylographic type, in which the signals are written down with ink on ordinary paper, either in the form of a wavy line or as dots and dashes. 


\section{(1) Photographic Recorders}

In this class, there were available the Einthoven galvanometer type and the Hoxie recorder of the General Electric Company. The former had been used to some extent by European radio companies, and the latter by the United States Navy, as well as on commercial work in Radio Corporation stations. Since the Hoxie apparatus was immediately available and obviously superior to the Einthoven galvanometer in type of record, mechanical construction, and so on, our attention was restricted to it.

The Hoxie recorder has already been discussed before this Institute and a description may therefore be omitted. This instrument has a number of advantages as a radio recorder; it delivers a fairly faithful record of the received signals and strays, has extraordinarily high speed capabilities (far in excess of what is actually required) and will work directly on a current of an order of magnitude the same as that used for good telephonic signals (15 microamperes). Thus it may be used directly in place of the operator's telephones, requiring no extra amplification, and forms a valuable instrument for purposes of research or oscillographic investigation where records over long periods of time (one or more hours) are desired, and the expense of the photographic tape is not objectionable.

\section{(2) Stylographic Recorders}

This class includes the Morse inker, and the siphon recorder. Both of these have been long used in telegraph and cable practice, and meet the important commercial requirements of instantaneous visibility of the recorded signal, cheapness, permanence of record, and continuous operation. Such other requirements as were not fulfilled by existing types of this apparatus (speed capability and mechanical simplicity) could obviously be met by further development; and, accordingly, we concluded that our attention should be centered along these lines.

\section{(a) Morse Inker (Wheatstone Automatic Recorder)}

Essentially, the Morse inker may be considered as a telegraph sounder (or polarized relay) carrying a small sharp-edged wheel on the end of the sounder armature, the edge of the wheel being kept moistened with rather thick ink, and with paper tape moving under the wheel. When the sounder magnets are energized by direct current the armature comes down and the inked wheel makes a dot or dash on the paper, depending upon the length 
of time the current remains on. The current required to operate a typical instrument is about $\mathbf{5 0}$ milliamperes, the resistance of the magnet windings being of the order of $1,000 \mathrm{ohms}$ (an energy requirement of about 2.5 watts). It will be recalled that the Morse inker and coherer formed the first type of radio receiving system ever used, and in Europe, to-day, the Morse inker is again being employed in high speed radio reception.

Two methods of connecting the inker to the receiving set have been used. In one, the audio frequency signal is amplified to an extent such that energy of the required order of magnitude may be furnished; but this is very cumbersome (since for this comparatively large amount of energy, power tubes and amplifiers using several hundred volts of plate battery are necessary) and really unnecessary in view of the type of record; so that it is generally more customary to operate the inker thru a relay. The simplest method is to place the magnet winding of a sufficiently sensitive telegraph relay in the plate circuit of a detector tube, so that when the direct plate current of the tube varies with the audio or radio frequency voltages impressed on its grid, the relay armature is operated, and the inker may be worked from the relay armature contacts. More complex, but also more reliable methods than this have been developed, and some of these are described in publications given under "Bibliography."

The Morse inker has the disadvantage that the record which it makes can only be a dot or dash. Thus, if strays in the form of individual clicks are present, in sufficient strength, a dot will be printed for each stray click. If the strays are more or less continuous (in the form of rapidly successive clicks or crashes) a continuous dash will be made. Therefore, the reading of a message thru static has been found by experiment to be much more difficult on Morse inker than on siphon recorder tape (in which the record is in the form of a wavy line). When the inker is operated thru a relay, the latter is tripped or held closed by the strays so that the inker is falsely operated; the effects of strays in this arrangement are even worse than if the inker is merely operated thru an amplifier.

It was judged most advisable, therefore, to work along the lines of the siphon type of record and to develop an instrument which, with a moderate amount of amplification, would record directly the rectified audio frequency current of the operator's signal. The requirements determined upon were that the instrument should work on a rectified current of a few milliamperes, and be capable of recording readily at the rate of 100 words per 
minute, with the capability of eventual extension to higher speeds by small alterations of the parts.

\section{(b) Siphon Recorder}

An examination of the existing types of siphon recorders was then made. All the commercial forms that we were aware of consisted essentially of the parts shown in Figure 5. In this instru-

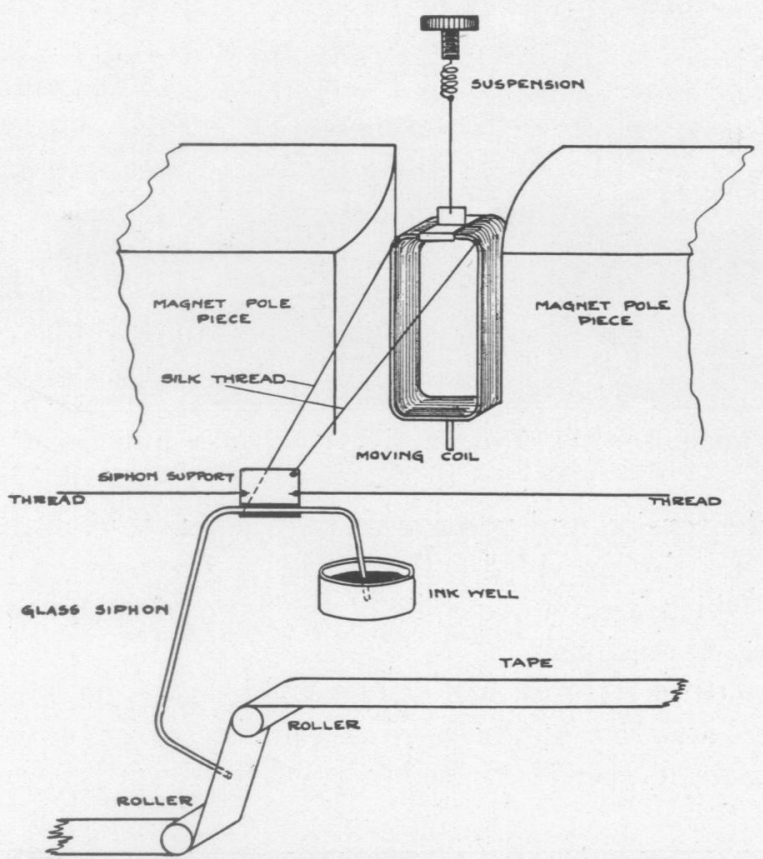

Figure 5-Elements of Siphon Recorder, Cable Tape

ment a galvanometer coil is placed between the poles of a powerful magnet so that when the current to be recorded passes thru the coil, it turns on its vertical axis; threads are attached to the upper corners of the coil form, which pull a small fiber piece called the "siphon support" as the coil rotates, so that the glass siphon travels back and forth over the moving tape. The siphon consists of a fine glass tube having a hole of the order of 0.01 inch $(0.25 \mathrm{~mm}$.), bent as shown in the figure, and secured to the support by wax. An ink well is placed above the tape and the end of the siphon allowed to dip into it; since the end of the siphon on the tape is lower than that in the ink well, the ink is caused to flow thru continuously. Adjustments for the height and angle of the tape, 


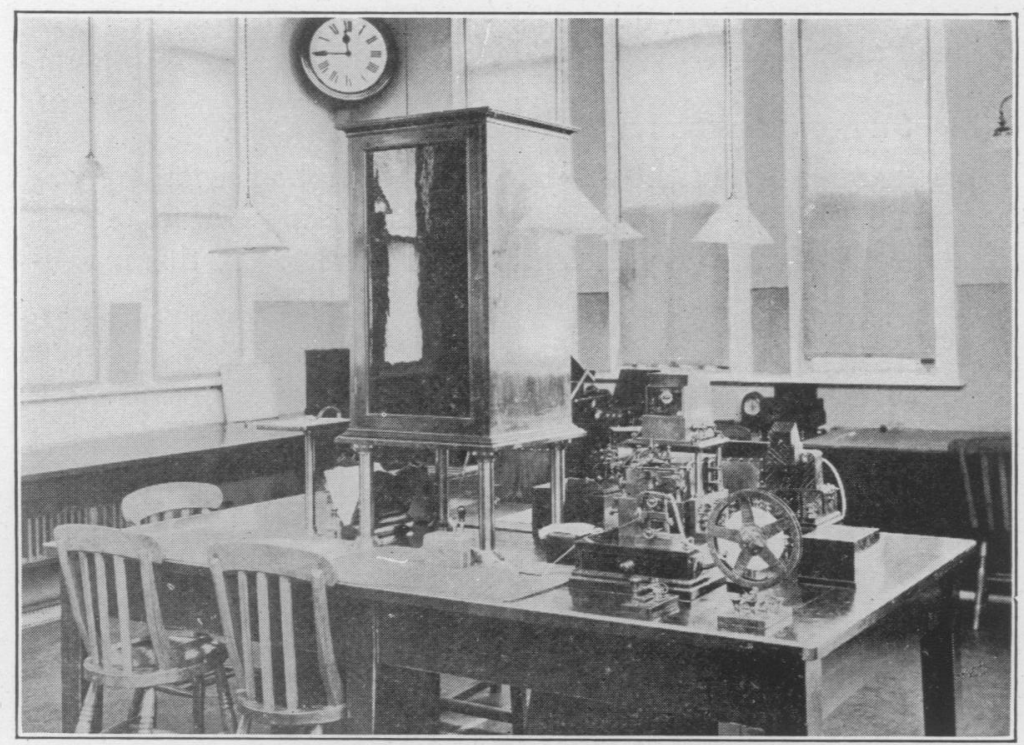

Figure 6-Cable Type of Siphon Recorder Installation

and for the tension and position of the various threads and suspensions are also provided. These will be best seen in Figures 6 and 7 , which are photographs of the type of siphon recorder used in cable stations.

This type of recorder will deliver good signals on a few hundred microamperes; but because of the cumbersomeness of the moving parts, its speed is limited to less than 50 words per minute.

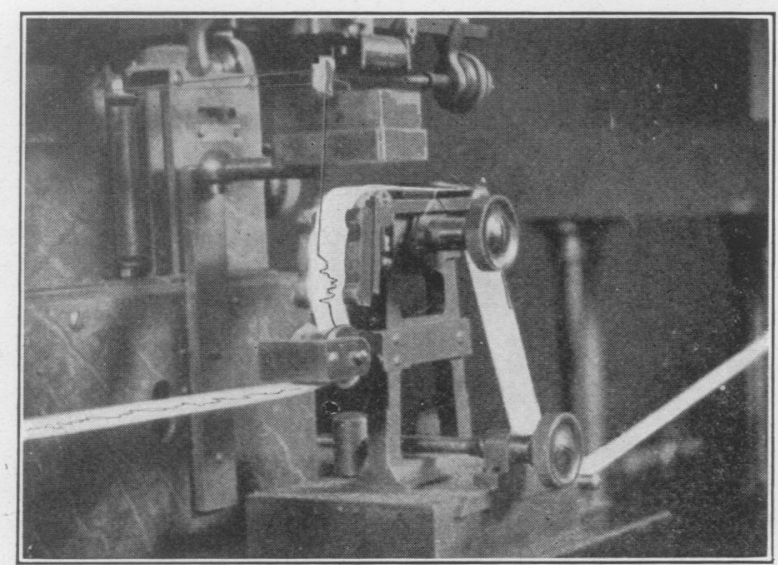

Figure 7-Cable Type of Siphon Recorder, Pen, and Tape Mechanisms 
Similar instruments, called "undulators," may be obtained which will record up to 100 words per minute, but which require currents of the order of 50 milliamperes, and would therefore have to be operated thru a relay as in the case of the Morse inker. In either case, the recorded signals at the higher speeds are badly rounded (instead of rectangular); a series of dashes appears as a set of "V's" following each other. Figure 8 indicates the type of record given by the cable type of siphon recorder on successive dashes at the comparatively moderate speed of 60 words per minute.

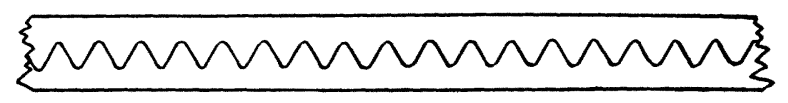

Figure 8-Record of Dashes at 60 Words per Minute on Cable Type of Siphon Recorder

In addition to the speed limitations, and poor type of record, the mechanical features of the siphon recorders which were available in the open market rendered them quite unsatisfactory for radio use. For example, the long glass siphon requires skill to make and mount, and in case of breakage or clogging it takes considerable time to put on a new one; while in connection with the various adjustments and general construction of parts it was felt that improvements could be made which would render the instrument more simple, convenient, and better adapted to meet. the rather rough usage such a device would receive in radio stations.

Accordingly, it was next decided to undertake the development of a mechanical form of recorder having the desired characteristics. The form which was developed was a distinct departure from the old cable type, and became known later on as the "Ink Recorder," by which title we shall refer to it hereafter.

\section{Mechanical Development of Ink Recorder}

The original idea and the mechanical development of this recorder are due to Mr. Edward Blakeney; and the design of the commercial apparatus to Mr. Blakeney and Mr. Samuel C. Miller, of the Research Department.

Without going into the various development models, with their usual record of small detailed changes, it will be best to doscribe only the final commercial type, since the essential parts remained practically the same thru the development. 
The essential parts of the recording system are indicated in Figure 9. A small circular coil is placed in the radial field produced by a powerful solenoid type of electromagnet; rising from the coil frame a link engages the pen arm. The latter is supported at one end by a thin, wide steel spring (called the fulcrum spring) and carries at its outer end a short piece of metal tubing, about half an inch $(1.27 \mathrm{~cm}$.) long, called the pen. This pen takes ink from a device called the "ink feed" at one end and writes on the paper tape at the other. The coil frame, pen arm, and link are made of thin aluminum sheet; the pen is a small size of brass tubing.

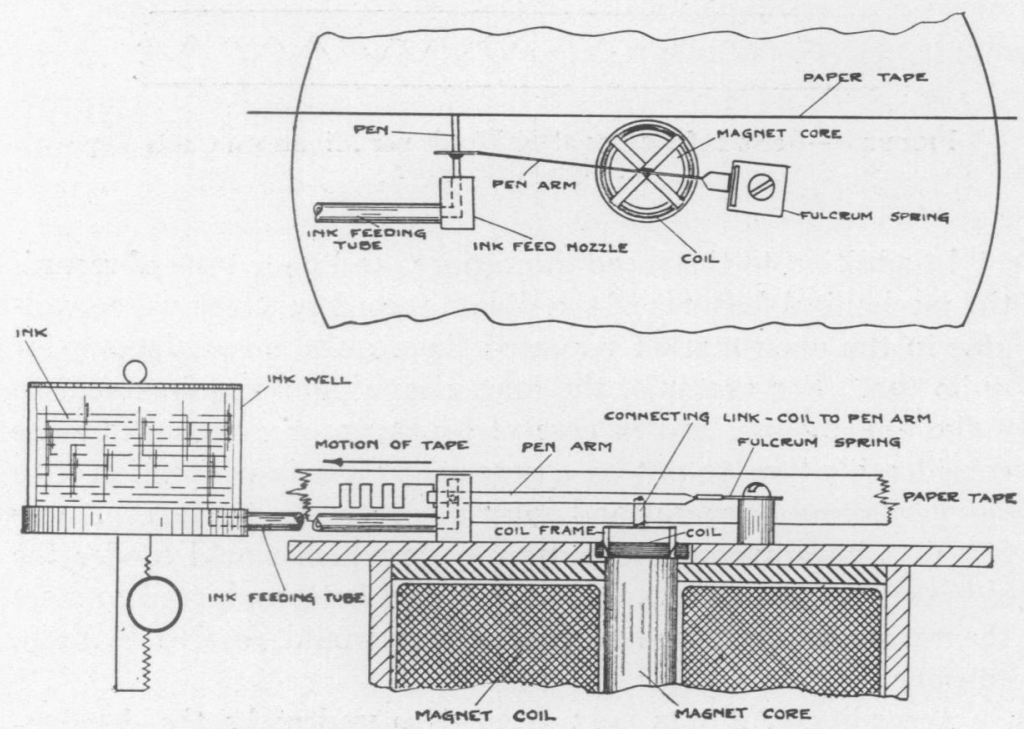

Figure 9 -Essential Elements of Ink Recorder

The ink feeding arrangement consists of a piece of brass having a deep rectangular slot along the end near the pen, and is known as the ink feed nozzle. The slot is connected thru a hole to the side of the nozzle, where a rubber tube is attached. This tube connects to an inkwell fixed at one side of the recorder. The inkwell may be regulated in height, with respect to the ink feed nozzle, by means of a rack and pinion. The level of the ink in the nozzle is at the same height as its level in the inkwell; but since the slot is only about one-sixteenth of an inch $(1.58 \mathrm{~mm}$.) wide, surface tension keeps the ink from spilling out of the slot and it forms a long rectangular bead on the face of the nozzle into this bead the pen dips. If the magnet is energized and 
signal current passes thru the small coil, it is pulled upwards. The link therefore pushes the pen arm up; the pen moves upward in the bead on the face of the ink feed nozzle, supplying itself with ink, by capillary action, as it goes, and makes a vertical line on the slowly moving tape. When the signal current stops, the restoring force of the fulcrum spring sends the coil back to its starting position.

The recorder coil has about 600 turns, a direct current resistance of $1,000 \mathrm{ohms}$, and the pen will produce a full-size record $(1 / 8$ inch $=0.32 \mathrm{~cm}$. $)$ with about 4 milliamperes thru the coil up to a speed of 100 words per minute. For higher speeds, the fulcrum spring is changed, and with 8 milliamperes, 200 words per minute may be recorded.

The arrangement of parts here indicated makesit possible to provide a much simpler and more rugged instrument than the old type of siphon recorder, while at the same time gaining in speed and sensitivity. Instead of the wide air gap in the magnetic circuit, as in the old recorders, a narrow gap is used and a very powerful field can be provided with a relatively small magnetizing force. The moving elements are reduced to a minimum in weight and size, giving the instrument high speed capability and sensitivity. In place of the long breakable glass siphon, a short metal one is used, which is made up as a unit with the pen arm. In case of trouble, a spare pen arm can be inserted in a few moments. All parts are easily dismounted and are also readily accessible for adjustment or repair without dismounting.

The commercial model of recorder is shown in Figures 10 (top view) and 11 (cross-section). On these it will be noted that $\mathrm{n}$ addition to the essential elements of Figure 10, there have been provided the following:

(a) Four threads, with height and tension adjustment screws, which are used to center the recorder coil.

(b) An adjustable tape guide, consisting of a brass form in which the tape is held taut and smooth, so as to afford a good writing surface for the pen.

(c) Clamps and adjustments for various parts.

(d) Brushes for cleaning paper dust from the tape before it enters the tape guide (to prevent clogging the pen).

(e) A glass-topped cover over the recording mechanism.

(f) A "damping device."

The last-named part requires some explanation, and is illus- 


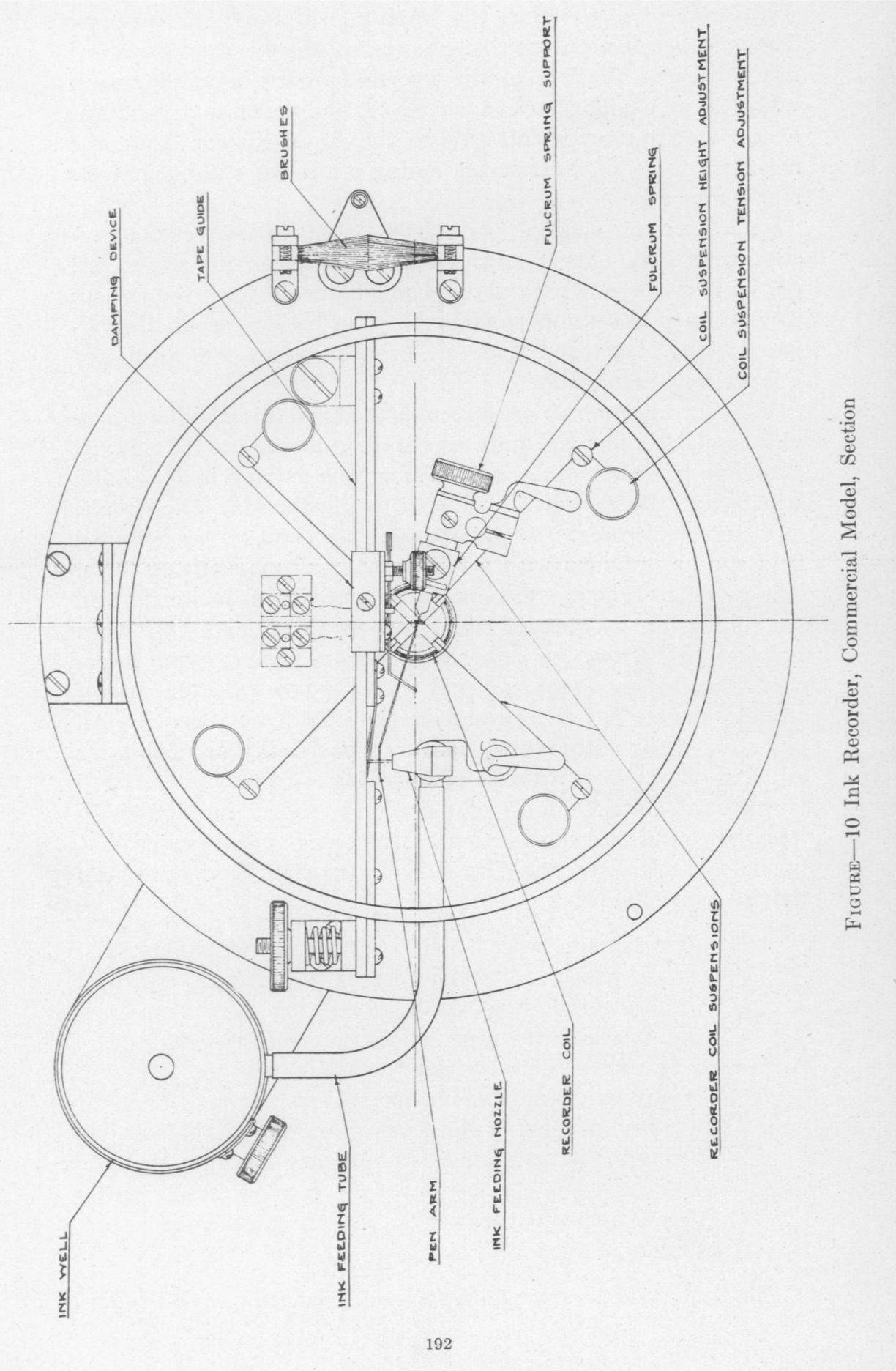




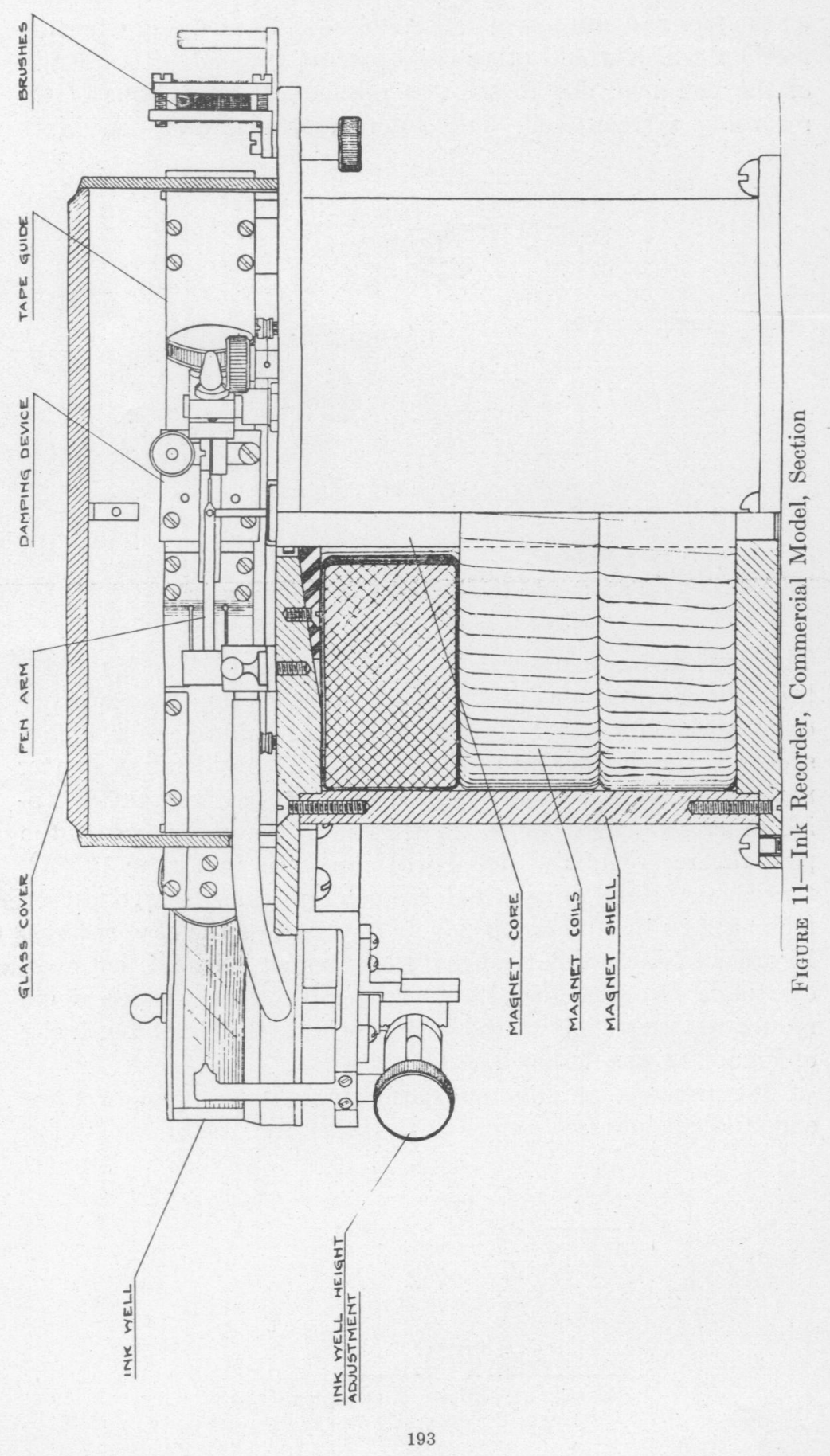


trated in greater detail in Figure 12. Its purpose is to square off the tops and bottoms of dots and dashes, by stopping vibrator: motions which would otherwise occur at the end of the stroke of the pen arm, due to the free mechanical oscillations of the recording system (coil, link, fulcrum spring, and pen arm)

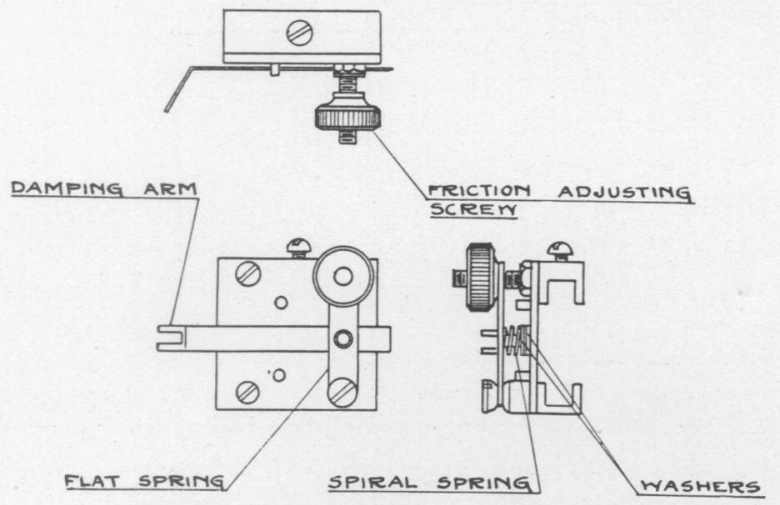

Figure 12-Ink Recorder Damping Device

This system has a natural frequency of about 35 cycles and a logarithmic decrement of about 0.7 (when equipped with a fulcrum spring for use below 80 words per minute;-for higher speeds a heavier spring is used having a considerably greater natural frequency). When allowed to operate without any damping other than that due to the friction of the paper against the pen, the record of the signal will appear as in Figure 13 (A): that is, at the end of its stroke the pen arm overshoots, and then falls back to the full amplitude or zero line, as the case may be. In order to damp this tendency to overshoot, without, however, exerting a damping effect thruout the entire stroke (which would reduce the amplitude of the entire record), the damping device of Figure 12 was designed.

It consists of an aluminum arm pivoted at a point near one end, and cut into two prongs at the other end. A brass counter-

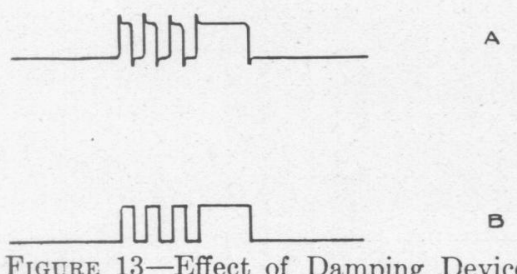


weight on the short end serves to balance the arm about the pivot. The pen arm rests between the two prongs (see Figure 10), the space between these being sufficiently large so that the pen arm has a free movement of about $1 / 16$ inch $(1.6 \mathrm{~mm}$.) without touching either prong. When the pen arm moves further than this, however, it strikes one or the other of the prongs and tends to carry the damping arm along with it. The freedom of movement of the damping arm is controlled by means of friction exerted by washers which press against the arm at its pivot, the pressure of the washers being regulated by means of a spiral spring which is compressed by a knurled-headed screw. Thus the motion of the pen arm is gradually checked as it approaches the end of its stroke and the signal can then be made to appear

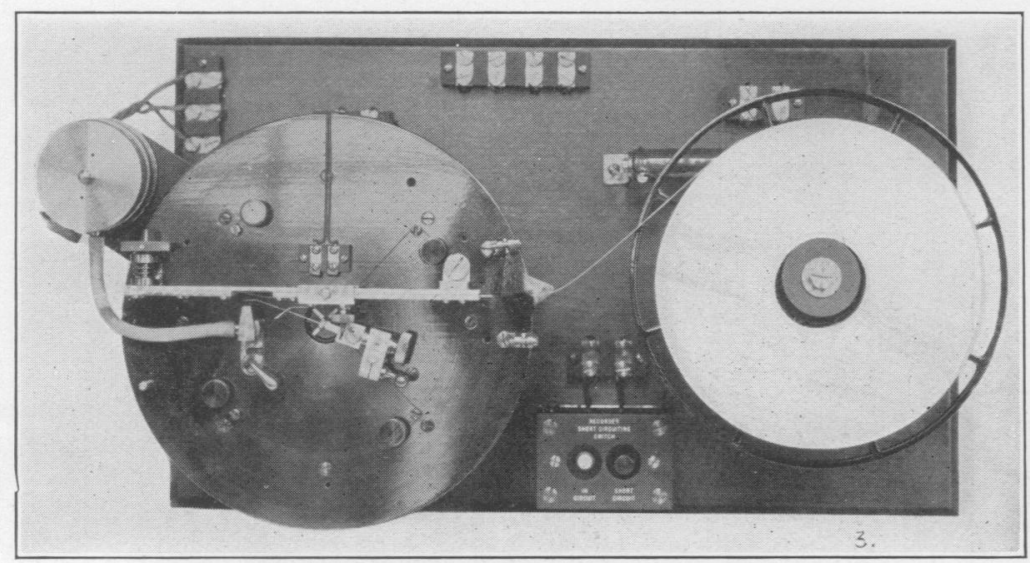

Figure 14-Ink Recorder and Tape Reel, Top View

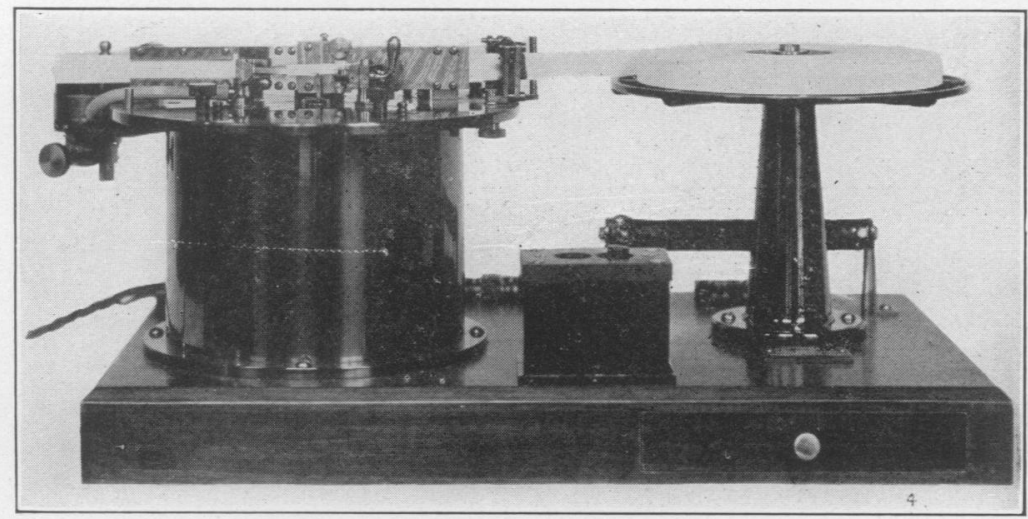

Figure 15-Ink Recorder and Tape Reel, Front View 


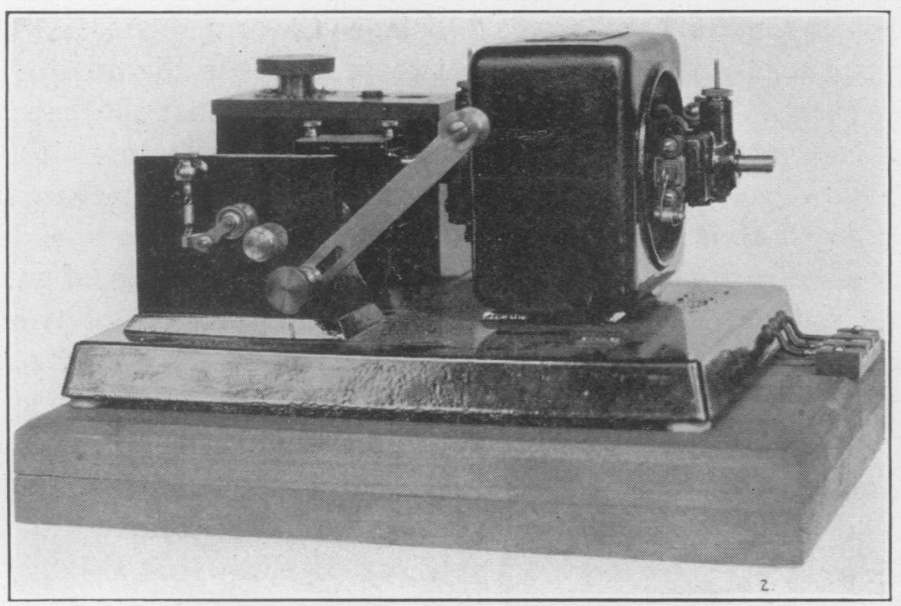

Figure 16-Tape Puller, Front View

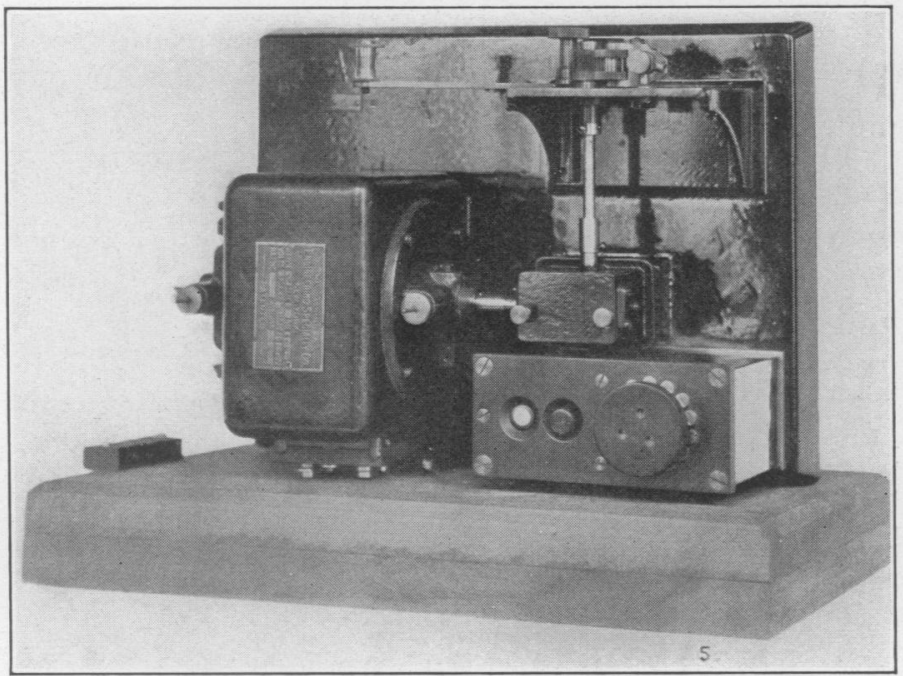

Figure 17-Tape Puller, Top View

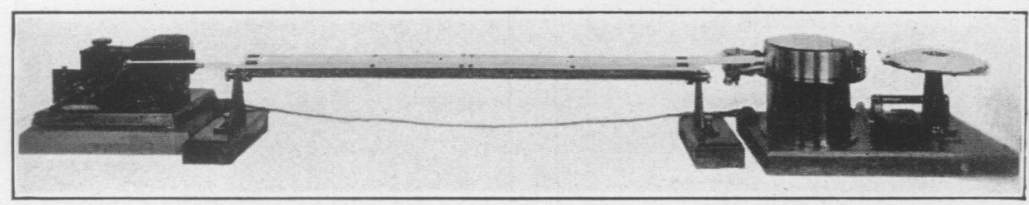

Figure 18-Assembly of Ink Recorder, Tape Puller, Reel, and Table 
square, as in Figure 13 (B). The finished commercial recorder and some of its accessory parts are shown in the photographs, Figures 14, 15, 16, 17, and 18. Figure 14 is a top view of the recorder assembled on a common base with the tape reel, Figure 15 the front view of the same, Figure 16 the machine for pulling the tape through the recorder (a standard commercial article known as a tape puller), Figure 17 a top view of the tape puller showing the motor speed control rheostat and gear box for reducing the motor speed to an appropriate value for the tapepulling wheel, and Figure 18 an assembly of the recorder and tape puller with a "tape table" between them. The tape passes over the latter, and the operator's typewriter is placed in a well below the middle of the tape table, so that he may typewrite directly from the tape.

\section{Amplifiers Associated with the Ink Recorder}

While the development of the recorder was being carried on, experiments were conducted simultaneously to determine a suitable amplifier system, the input of which was to be connected to the radio receiving equipment in place of the operator's telephones and the output of which was to supply the recorder with a direct current of 2 to 4 milliamperes, thru the $1,000 \mathrm{ohm}$ recorder coil. Aside from furnishing the required amplification, it was desired to utilize the amplifier circuits to secure as great a discrimination as possible between the signal audio frequency and strays.

For this purpose a number of amplifier circuits were set up and comparative records made on two identical recorders simultaneously, the signals from a local oscillator ${ }^{1}$ being sent into a receiving antenna and their intensity regulated so that any desired ratio between signals and natural strays could be obtained. The amplifier under test was connected to one recorder, and a standard amplifier to the other recorder; the output of the receiving set being fed to both amplifiers at once. In this fashion an accurate and quick determination of the merits of any particular amplifier circuit could be made. This method of comparison yields much more dependable results than the method of taking sequential records on the same recorder with different amplifiers; strays are so exceedingly variable in their intensity and character from one minute to the next that the sequential method will lead to quite erroneous conclusions - as we found by experience.

${ }^{1} \mathrm{~J}$. Weinberger and C. Dreher: "An Oscillation Source for Radio Receiver Investigations, "Proceedings of The Institute of Radio Enginemr, volume 6 , page 584,1919 . 
The amplifier circuits which were tested are shown in Figure 19. In every case, the tubes used were the Radio Corporation's type UV 202 (filament, 7.5 volts, 2.35 amperes, internal resistance $7,000 \mathrm{ohms}$ ), which are the standard receiving tubes in our stations; the plates were supplied from 220 volts, direct current, the local power lines being used thru suitable filters (to diminish line hum). The last amplifier tube always fed a step-down transformer, which was connected to a rectifier tube in series with the recorder.

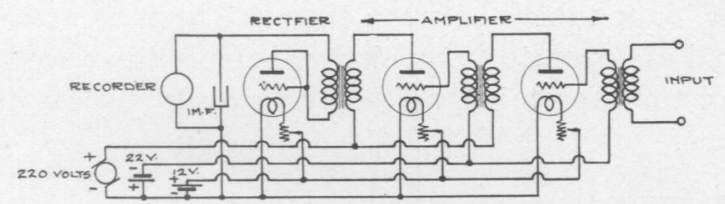

(A) and (B)

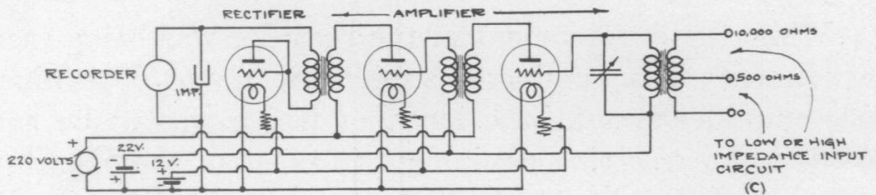

(C)
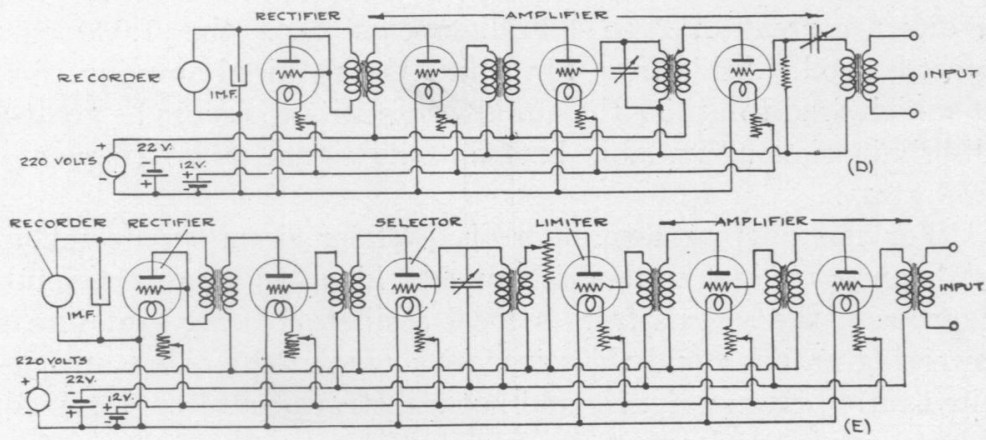

FIgURe 19-Experimental Ink Recorder Amplifiers

Five types of audio frequency amplifiers were tried, viz.:

(A) Two stages of untuned, air-core transformers known as the "Century" type, made by the Federal Telephone and Telegraph Company, Buffalo, New York, having the following constants: primary, 5,300 ohms direct current resistance, 3.4 henrys inductance, 9,700 turns of $3 \mathrm{mil}(0.076 \mathrm{~mm}$.) enameled wire; secondary, $37,000 \mathrm{ohms}$ direct current resistance, 75 henrys inductance (at 800 cycles), 58,000 turns of 3 mil $(0.076$ $\mathrm{mm}$.) enameled wire. This amplifier was built in order to deter- 
mine whether the signal-stray ratio of the air-core transformers was superior to that of iron-core transformers.

(B) The same as (A) but with closed iron-core transformers instead of air-core. These transformers were the Radio Corporations's type UV 712, having the following constants: Primary,

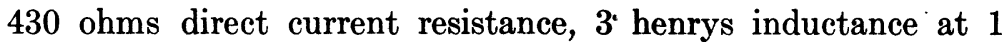
milliampere and 800 cycles; secondary, 5,100 ohms direct current resistance. Ratio of turns, 9 to 1 .

(C) One stage having a tuned transformer followed by one stage having an untuned transformer (type UV 712, as in case B). The tuned transformer consisted of two coils, the primary having 8,400 turns with a tap at 1,200 turns (for use in high or low impedance input circuits respectively); the secondary having 29,000 turns of $3 \mathrm{mil}(0.076 \mathrm{~mm}$.) enameled wire, on a common laminated iron core 3.5 inches $(8.85 \mathrm{cms}$.) long and 0.5 inch $(1.27 \mathrm{~cm}$.) square. With a variable condenser of 0.001 microfarad capacity across the secondary the transformer could be tuned to any frequency in the range from 700 to 1,600 cycles. This transformer was the result of previous experiments along similar lines, and its tuning was sufficiently broad to take account of the normal fluctuations in frequency which might be expected at present in the reception of foreign alternator stations (approximately 100 cycles above or below a mean frequency of 1,000 producing a reduction of current to 75 per cent of full amplitude, or equivalent to a logarithmic decrement of about $0.6)$.

(D) One stage having a tuned transformer circuit of very high resistance, the resistance chosen being 0.7 of the critical damping resistance for the circuit; this followed by the same type of two-stage amplifier as in case of (C), that is, one tuned and one untuned stage. The purpose of this arrangement was to make a practical test of the following theory:

The natural frequency at which a circuit will oscillate, if shock excited, is given by the well-known expression

$$
f=\frac{1}{2 \pi} \sqrt{\frac{1}{L C}-\left(\frac{R}{2 L}\right)^{2}}
$$

However, if the circuit is subjected to a sustained alternating electromotive force, the maximum current will flow when

$$
f=\frac{1}{2 \pi} \sqrt{\frac{1}{L C}}
$$

That is, the resistance plays a part in determining the natural 
frequency of the transient circuit oscillations, but does not affect the "resonance" frequency. Hence, if the resistance is made as large as 0.7 of the critical damping resistance, the circuit will still oscillate, but at a frequency 0.7 that of the "resonance" frequency. With the particular tuned transformer used, this resistance was 300,000 ohms. Now, if this circuit was followed by a comparatively sharply tuned circuit, it was expected that the free oscillations due to strays would be at a frequency of 700 cycles when the signal frequency was 1,000 cycles, and the tuned circuit (set at 1,000 cycles) would respond more strongly to the signals than to the strays.

(E) An amplifier circuit involving "limiting" action, followed by audio frequency selection. This was based on the theory that if strong strays were reduced to an amplitude equal to that of the signal, by means of a "limiting" tube, then it would be possible to gain an advantage in signal-stray ratio by "picking out" the signal (which would have a definite audio frequency) with a sharply tuned circuit from amongst the strays (which would be of equal amplitude but of no definite frequency). To secure this result, a two-stage amplifier containing untuned air-core transformers was placed ahead of the limiting tube, and the latter was followed by an amplifier of type (C). A potentiometer in the plate circuit of the limiter controlled the amount of energy fed to the selecting circuit, so that the tube connected thereto would not be overloaded.

The conclusions drawn from numerous experiments with the above amplifiers were as follows:

(1) Air-core versus iron-core amplifying transformers (type $A$ versus type $B$ amplifier): No essential difference in behavior was found towards strays; it was concluded that the particular types of transformers tested could be used interchangeably in this work.

(2) Tuned versus untuned amplifier (type $\mathrm{C}$ versus type A): The tuned amplifier is moderately superior to the untuned one, on heavy strays. The advantage is not a great one, and during conditions which are suitable for high speed working (that is, light strays) there is no particular loss in dispensing with tuning. However, there is an advantage in the use of tuning, namely, that of discrimination against other interfering sustained audio frequencies, such as the compensation wave in the reception of arc transmitters, or the elimination of telephone line noises due to power line induction (which must be reckoned with in any system using wire line transfer of the received signals). It must 
also be remembered that the sharpness of tuning permissible in the amplifier transformer was limited by the fact that a certain amount of frequency fluctuation of the transmitter had to be reckoned with; it is possible that with very sharply tuned circuits greater advantages might be gained.

(3) Tuned amplifier type (C) versus tuned amplifier type (D): No appreciable difference in the behavior of these two types was found in the circuit under test and with this type of recorder; it was therefore concluded that there was no special advantage in the extra complication of type (D).

(4) Tuned amplifier type (C) versus limiting followed by audio frequency selection (type E): In the circuits shown, it was found that the strays had a slight tendency to mutilate the letters more badly with type (E) than with the simple tuned amplifier. This effect might have been due to the fact that a stray crash consists of many overlapping impulses, and when the signal was added on to these, the limiter temporarily passed on no signal for the audio frequency circuit to select. Hence, a letter would be broken more badly in this case than in the tuned amplifier employing no limiting ahead of the selecting circuit.

Therefore, it was decided that the tuned amplifier of type (C) was the best to use with the recorder for the present.

It is probable that a more extended investigation into the subject of amplifiers for the reduction of the stray-signal ratio would lead to profitable results, particularly on the assumption that a frequency constant to within one-tenth of one percent in foreign transmitters may be expected in the future; and this work is being continued.

\section{Typical Ink Recorder Installations}

The method of installation employed at outlying receiving stations is indicated in Figure 20. The recorder, tape puller, and tape carriage are mounted on a common table, and a typewriter well is placed so that the operator may copy directly from the tape. The amplifier is mounted on a panel conveniently near the recorder, so that tuning or other adjustments may be made while their effect on the record is observed.

In the central station at 64 Broad Street, New York City, the layout and method of operation of which is due to the Traffic Department of the Radio Corporation, the amplifier equipment is placed in an apparatus room separate from the operating room. Here a special amplifier is employed in which the ampli- 
fications necessary both for wire line transfer and recording are combined. The recorder is placed beside the operator.

The above method of having one operator copy directly from the tape is suitable up to a speed of about 45 words per minute. Above this speed several operators may read the tape in succession, in the manner used in cable offices. That is, one man is placed near the recorder, a second perhaps ten feet (3 meters) along the tape, and a third man ten feet further along. The

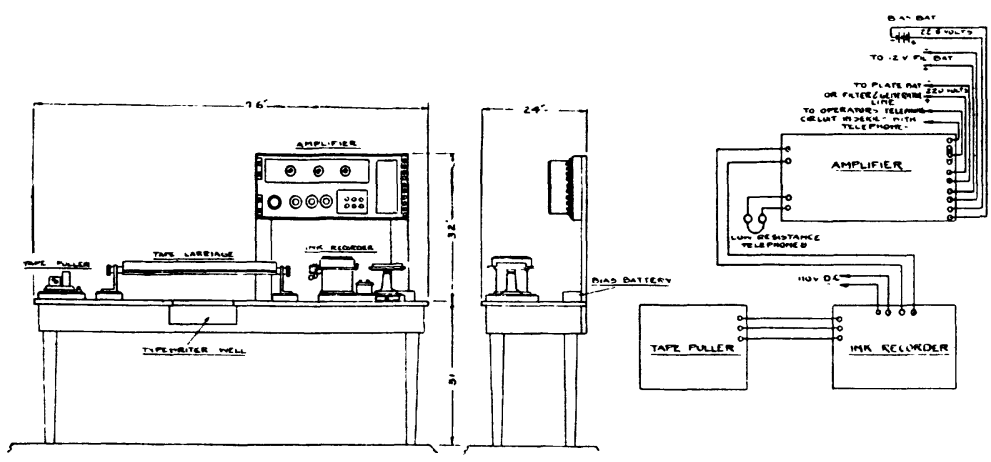

FIgURE 20-Ink Recorder System: Typical Installation at Outlying Stations

first man copies from the tape, which is moving faster than he can keep up with, until he reaches a point such that the signals are nearly out of easy sight. He then stops copying, marks the point on the tape at which he stopped, and starts in again as near the recorder end of the tape as he can see easily and marks on the tape the point at which he has started again. The second man then starts copying at the point at which the first man left off and copies the intervening material, either up to the point at which the first man started again, or else as far as he can. If he cannot read all the material omitted by the first man he also marks the point at which he left off, and the third man completes the copy of the omitted material. By this method the transcription of traffic at 100 words per minute by three men is readily possible.

Figure 21 is a photograph of part of the Broad Street operating room, in which some of the recorders may be plainly seen. In this office, a recorder is placed on each trans-oceanic receiving circuit, and, in addition, arrangements are being made to keep a record of the outgoing signals from each transmitter. This is accomplished by means of an antenna on the roof of the building, connected to receiving sets and recorders in the apparatus 
room; this equipment easily receives all of the local transmitting stations, and the signal leaving the sending operator's key or Wheastone transmitter may thus be directly compared with the signal radiated from the transmitting station's antenna. In this way, line or relay faults, trouble in the transmitting station, and the like, may be instantly noticed, and a check also kept on operating errors.

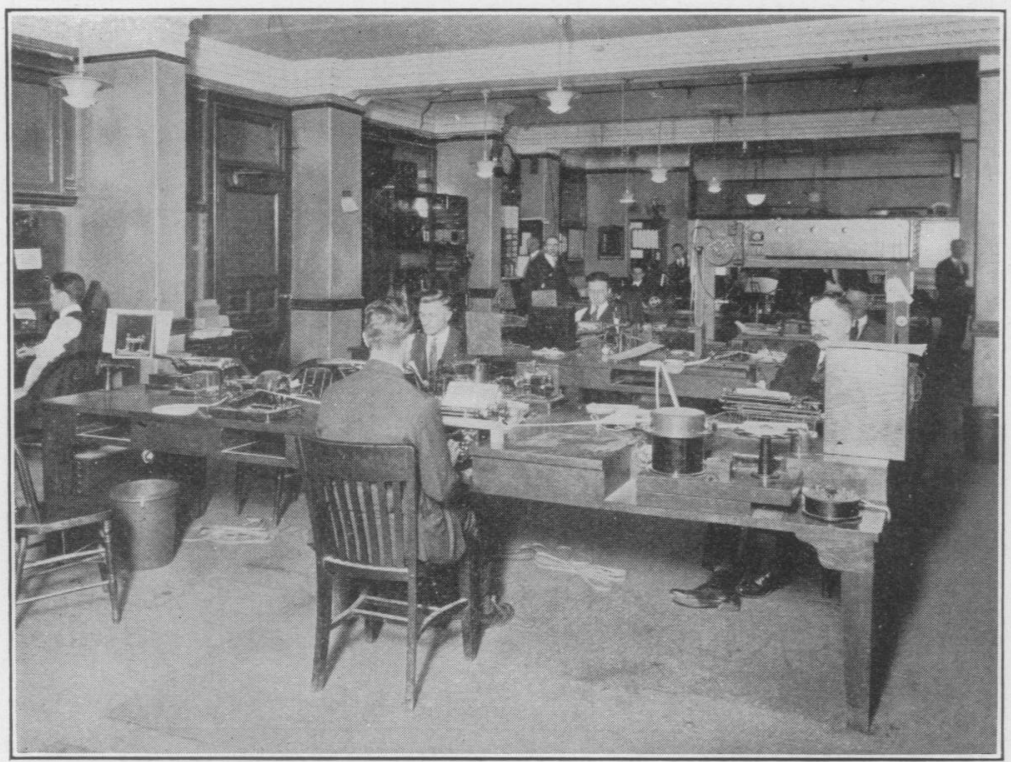

Figure 21-Part of Operating Room, Broad Street (New York City) Office Radio Corporation of America

\section{TyPICAL RECORDS}

In Figure 22 a number of typical tape records taken on the ink recorder are reproduced. These show plainly the speed capabilities of the instrument and the clearness of the records obtainable. The first three illustrations are of a series of test letters, "YI5," recorded at various speeds (these letters having been arbitrarily chosen because of the manner in which they display the operation of the instrument on various dot and dash combinations). All but one of the remaining illustrations are of various European transmitters recorded in the United States, while the last one is a record of the valve transmitter at Geneva (Switzerland), used on the Geneva-London radio circuit, taken on the ink recorder system at an English station. 


\section{ACKNOWLEDGMLNTS}

The author desires to acknowledge his gratitude to the following: Dr. Alfred N. Goldsmith, Director of the Research Department, for his kindly encouragement during this development and his valuable suggestions; Messrs. Edward T. Dickey and Carl Dreher, of the Research Department, for their thoro and painstaking assistance and their supervision of the laboratory and field tests of the system; Mr. W. A. Winterbottom, Traffic Manager, and the officials of the Traffic and Engineering Departments, of the Radio Corporation, for their criticism and support; and finally, the operating staff of the Belmar station, who contributed much practical and encouraging criticism during the field tests of the first models.
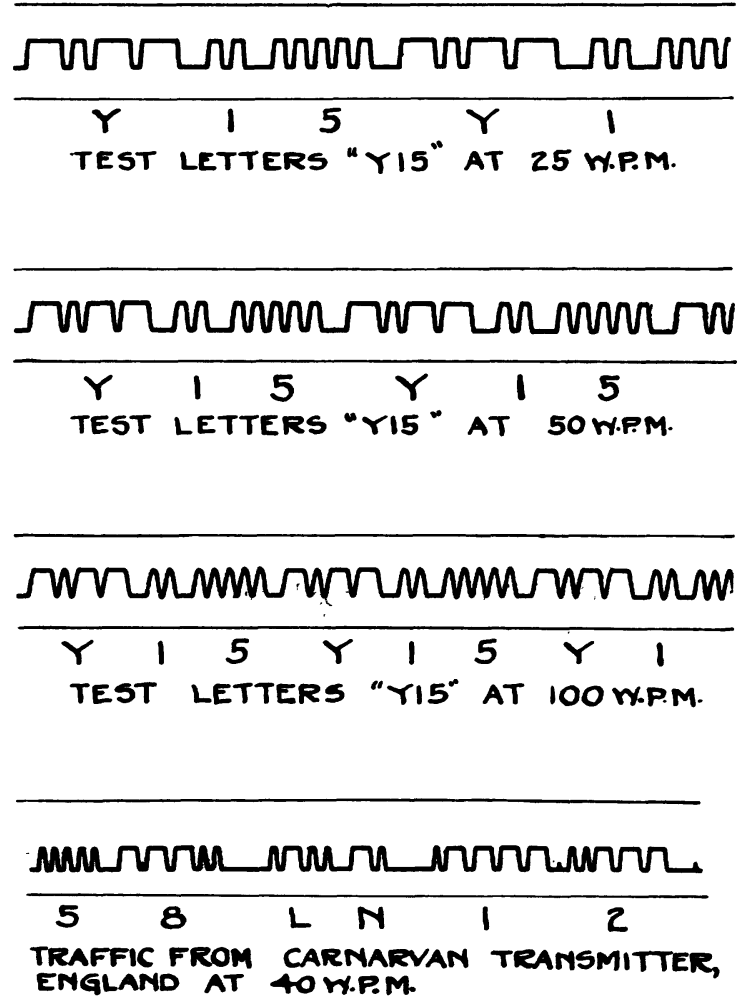

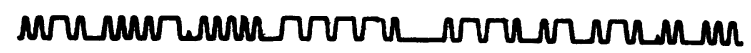

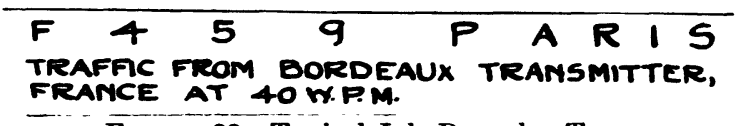

Figure 22-Typical Ink Recorder Tapes 


\section{BIBLIOGRAPHY}

General Descriptions

J. A. Fleming: "The Principles of Electric Wave Telegraphy and Telephony" (Third Edition), pages 708-719.

E. Nesper: "Handbuch der drahtlosen Telegraphie und Telephonie," (J. Springer, Berlin, 1921), volume 2, pages 243-252.

\section{Telegraphone}

P. Dosne: "Recording Radio Signals by Means of the Telegraphone," "Comptes Rendus," volume 158, pages 473-474, February 16, 1914.

\section{Photographic Recorders}

T. Wulf: "Employment of the String Electrometer in Wireless Telegraphy," "Physikalische Zeitschrift," volume 15, pages 611-616, 1914.

H. Abraham: "Application of a Microgalvanometer with Continuous Photographic Registration," "Soc. Int. Elect. Bull.," 3rd Series, 3, page 649, 1913.

H. Simon: "The Electromagnetic Photographic Recorder as Receiving Instrument in Radio Telegraphy," "Jahrbuch d. drahtl. Tel. und Tel.," volume 2, pages 409-416, 1909. (Photographic Recorder of the C. Lorenz Company).

C. A. Hoxie: "A Visual and Photographic Device for Recording Radio Signals," Proceendings of The Institute of Radio Engineers, December, 1921.

Stylographic Recorders. (Morse Inker, Siphon Recorder, AND THE LIKE)

(In the following, references concerning the early use of coherer and Morse inker are omitted.)

A. Turpain: "Graphic Registration of the Eiffel Tower Signals," "Revue Electrique," volume 18, pages 211-214, 1912.

A. Turpain: "Reception of Wireless Signals in Morse Script by the Aid of Extra Sensitive Relays," "Soc. Int. Elect. Bull.," volume 3, 3rd Series, page 299, 1913.

A. A. Campbell Swinton: "Recent Improvements in Recording of Signals in Wireless Telegraphy," "Electrician," volume 72, page 687,1914 . (Cable type siphon recorder with S. G. Brown's relays.)

Raymond Barker: "Recording Radio Signals," "Electrician," volume 72, page 783, 1914. (Morse inker and Orling cable relay.)

A. A. Campbell Swinton: "Wireless Telegraphic Printing on 
the Creed Automatic System," "Wireless World," (London), volume 8, page $641,1920$.

F. Kiebitz: "Recent Researches in Radio Telegraphy," "Telegraphen und Fernsprechtechnik" (Berlin), volume 9, page 88,1920 . (Special relay and vacuum tube circuits with Morse inker.)

"The Hall Recorder." "Science and Invention," New York, page 1099, February, 1921. (Special type of hot-wire acoustic relay, and siphon recorder.)

Modern Practice in Operation of High Speed Radio Systems

H. Verch: "High Speed Telegraphy at High Power Radio Stations," "Telefunkenzeitung" (Berlin), March, 1921, page 7. (Recent German developments in apparatus.)

F. Banneitz: "Experiments and Results in High Speed Radio Telegraphy," "Telegraphen und Fernsprechtechnik" (Berlin), volume 9, page 90, 1920. (Experiences of the German National Telegraphic Research Laboratory in the development of national radio services, and the Berlin-London Radio Circuit.)

"The Geneva-London Radio Circuit," "Radio Review," (London), volume 2, page 535, 1921.

"The Paris-London Radio Circuit," "Radioelectricité" (Paris), volume 1, page 404, 1921, and volume 2, page 60, 1921. 